\title{
DETERMINATION OF A COEFFICIENT OF THERMAL EXPANSION BY MACHINE LEARNING
}

\author{
${ }^{1}$ Mario MACHU゚, '1'ubomíra DROZDOVÁ, 'Bedřich SMETANA, ${ }^{1} J a n$ RŮŽIČKA, ${ }^{1}$ Simona ZLÁ, \\ ${ }^{1}$ Svetlana SOROKINA
}

${ }^{1}$ VSB - Technical University of Ostrava, Ostrava, Czech Republic, EU, mario.machu@vsb.cz

https://doi.org/10.37904/metal.2020.3462

\begin{abstract}
Objective of this work is to model the thermal expansion coefficients of selected steel grade and compare results with those measured by TMA method. Coefficient of thermal expansion is described as a function of steel composition ( $\mathrm{C}, \mathrm{Mn}, \mathrm{P}, \mathrm{S}, \mathrm{Si}, \mathrm{Cr}, \mathrm{Ni}, \mathrm{Mo}$ ) and temperature.Experimental values are described and compared with model. Correlation analysis of these data sets is done. Presented model is based on using artificial neural network and represents a preliminary test of method capability to be used for such problems class - for predicting of thermophysical properties depending on composition and temperatre.
\end{abstract}

Keywords: Coefficient of thermal expansion, artificial neural network, material proporties, modelling

\section{INTRODUCTION}

The introduction should provide a clear statement of the study, the relevant literature on the study subject and the proposed approach or solution.

Using of methods based on artificial neural network (ANN) in material engineering became a promising way for predicting a wide variety of steel properties [1-4]. ANN also are capable of helping with design of new material of desired properties [5]. Thermophysical properties depending on material and its composition, temperature or even previous forging operations and heat treatment are not easy to obtain from commonly available literature [6-8]. One of those properties could be coefficient of thermal expansion (CTE) which is important in predicting of thermal stresses during manufacturing of goods or use of them.

Thermal expansion of material results in thermal stresses in material which can lead to yielding or cracking if the stresses are sufficiently high. In some applications (gas /steam turbines, parts of car engines, etc.) it is crucial to minimize thermal stresses by selecting material with low or similar CTE in mutually interacting components. There is a strong correlation between chemical composition, temperature and values of CTE so the relationship between them needs to be studied [9].

Neural network has the advantage of being fast, flexible efficient and accurate tool to predict and model highly nonlinear multidimensional relationships. Due to the flexible modeling and learning capabilities of ANN, it is possible to solve complex problems without any mathematical relationships between inputs and outputs. This method also reduces the need for experimenal work and time-consuming regression analyses.

\section{ARTIFICIAL NEURAL NETWORK MODEL}

An ANN has non-linear basic processing units called neurons. The neuron model and architecture of a neural network describe how a network transforms its inputs into outputs. The neural network architecture consists of multiple layers of neurons which have a summing up junction and a transfer function. A single neuron (Figure 1) transmits an input $p$ through the connection that multiplies its strength by the weight $w$ to form a product wp. A bias $\mathrm{b}$ is then applied - it is much like a weight with a constant value of 1 but can be omitted. 
The transfer function then produces the neuron output $Y$ using the product wp and bias. There are various transfer functions, most commonly used are sigmoid and linear. The central idea of an ANN is to adjust weights and biases, or the network itself adjusts these parameters to achieve accurate results - desired output values.

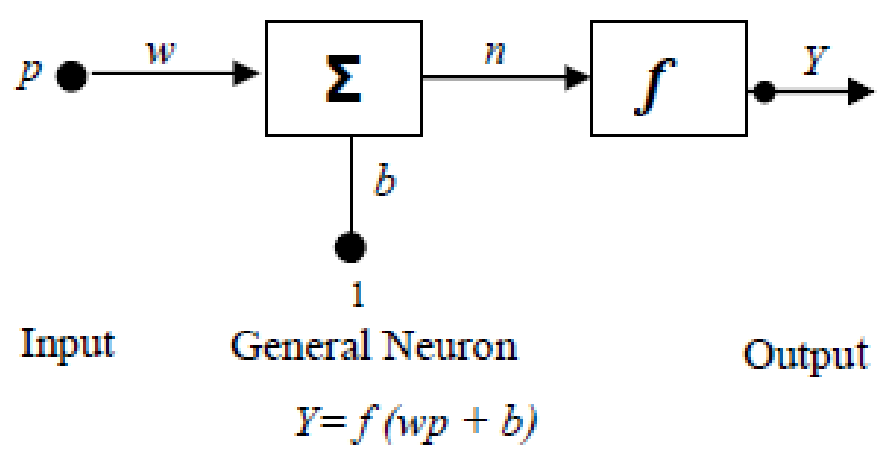

Figure 1 Simple neuron

The most commonly used neural network architecture for predictive type of tasks is given in Figure 2.

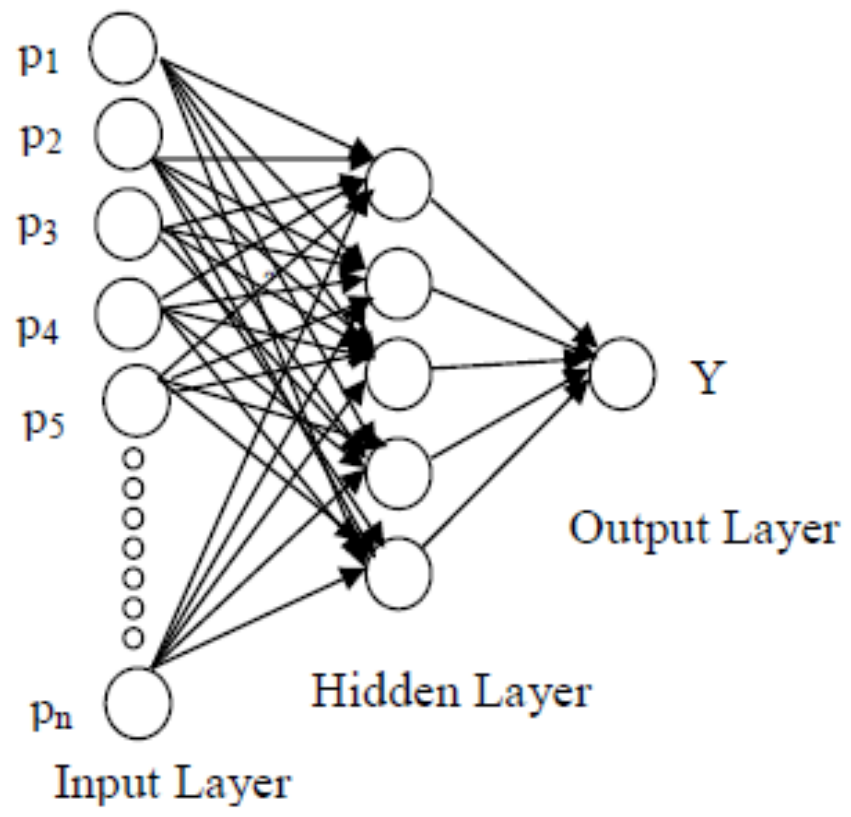

Figure 2 Multiple layer perceptron architecture

It consists of one input layer, one output layer, and one hidden layer. The added hidden layer contains intermediary parameters that are automatically generated by the model; the hidden layer is necessary in case of complex non-linear relationships between the inputs $p$ and the output $Y$. One or multiple neurons connect the input to the hidden layer. Similarly, one or multiple neurons connect the hidden layer and the output layer.

\subsection{Methodology}

The chemical compositions of the materials used in modelling are summarized in Table 1. Grades $1-9$ are described in [8], $10-11$ in [9]. Those and temperature (from $10 \mathrm{~K}$ to solidus temperatures) represent inputs to the model. The output of the model is a value of CTE. 
Table 1 Steel grades used for model

\begin{tabular}{|c|c|c|c|c|c|c|c|c|c|}
\hline Grade & Element & $\mathbf{C}$ & $\mathbf{M n}$ & $\mathbf{P}$ & $\mathbf{S}$ & $\mathbf{S i}$ & $\mathbf{C r}$ & $\mathbf{N i}$ & $\mathbf{M o}$ \\
\hline 1 & wt.\% & 0.150 & 2.000 & 0.200 & 0.150 & 1.000 & 18.000 & 9.000 & 0.600 \\
\hline 2 & wt.\% & 0.080 & 2.000 & 0.040 & 0.030 & 1.000 & 19.000 & 9.250 & 0.000 \\
\hline 3 & wt.\% & 0.030 & 2.000 & 0.045 & 0.030 & 1.000 & 17.000 & 12.000 & 2.500 \\
\hline 4 & wt.\% & 0.080 & 2.000 & 0.045 & 0.030 & 1.000 & 17.000 & 12.000 & 2.500 \\
\hline 5 & wt.\% & 0.080 & 2.000 & 0.045 & 0.030 & 1.000 & 19.000 & 13.000 & 3.500 \\
\hline 6 & wt.\% & 0.080 & 2.000 & 0.045 & 0.030 & 1.000 & 18.000 & 10.500 & 0.000 \\
\hline 7 & wt.\% & 0.080 & 2.000 & 0.045 & 0.030 & 1.000 & 18.000 & 11.000 & 0.000 \\
\hline 8 & wt.\% & 0.150 & 1.000 & 0.040 & 0.030 & 1.000 & 12.500 & 0.000 & 0.000 \\
\hline 9 & wt.\% & 0.120 & 1.000 & 0.040 & 0.030 & 1.000 & 17.000 & 0.000 & 0.000 \\
\hline 10 & wt.\% & 0.077 & 0.635 & 0.021 & 0.008 & 0.201 & 0.049 & 0.027 & 0.003 \\
\hline 11 & wt.\% & 0.162 & 0.707 & 0.012 & 0.007 & 0.191 & 0.046 & 0.0260 & 0.005 \\
\hline 12 & wt.\% & 0.150 & 1.11 & 0.030 & 0.020 & 0.500 & 6.63 & 3.170 & 0.410 \\
\hline Min & wt.\% & 0.030 & 0.635 & 0.012 & 0.007 & 0.191 & 0.046 & 0.000 & 0.000 \\
\hline Max & wt.\% & 0.162 & 2.000 & 0.200 & 0.150 & 1.000 & 19.000 & 13.000 & 3.500 \\
\hline Mean & wt.\% & 0.099 & 1.577 & 0.053 & 0.037 & 0.854 & 14.145 & 6.982 & 0.828 \\
\hline
\end{tabular}

The MATLAB Neural Network Toolbox is used for the optimization of the ANN architecture. To avoid overfitting inputs and targets are subdivided into three subsets - training $(70 \%)$, validation (15\%) and testing (15\%) subset randomly. Over-fitting leads to an inability of the network to provide accurate predictions for new sets of inputs, so over-fitted model can only accurate correlate the given inputs.

Training subset (only) is used to develop the model. The validation subset is used to limit over-fitting preventing the model from memorizing only a given data set and inability to model a new data set with unknown values of targets. The test subset is used for checking the generalization capacity of the network - the ability to provide an accurate prediction of unknown CTE for a new composition of steel and temperature.

\subsection{Results}

Several ANN were build; the best five architectures were stored. Correlation between outputs and targets for them are depicted in Figure 3. The neural network consisted of multilayer perceptron (MLP) with nine input neuron (8 for composition, 1 for temperature), eight hidden neurons in the hidden layer and one output neuron with tanh activation function between inputs and hidden layer and identity transformation function before output neuron was used.

Previously not used steel grade (12 from Table 1) was used for

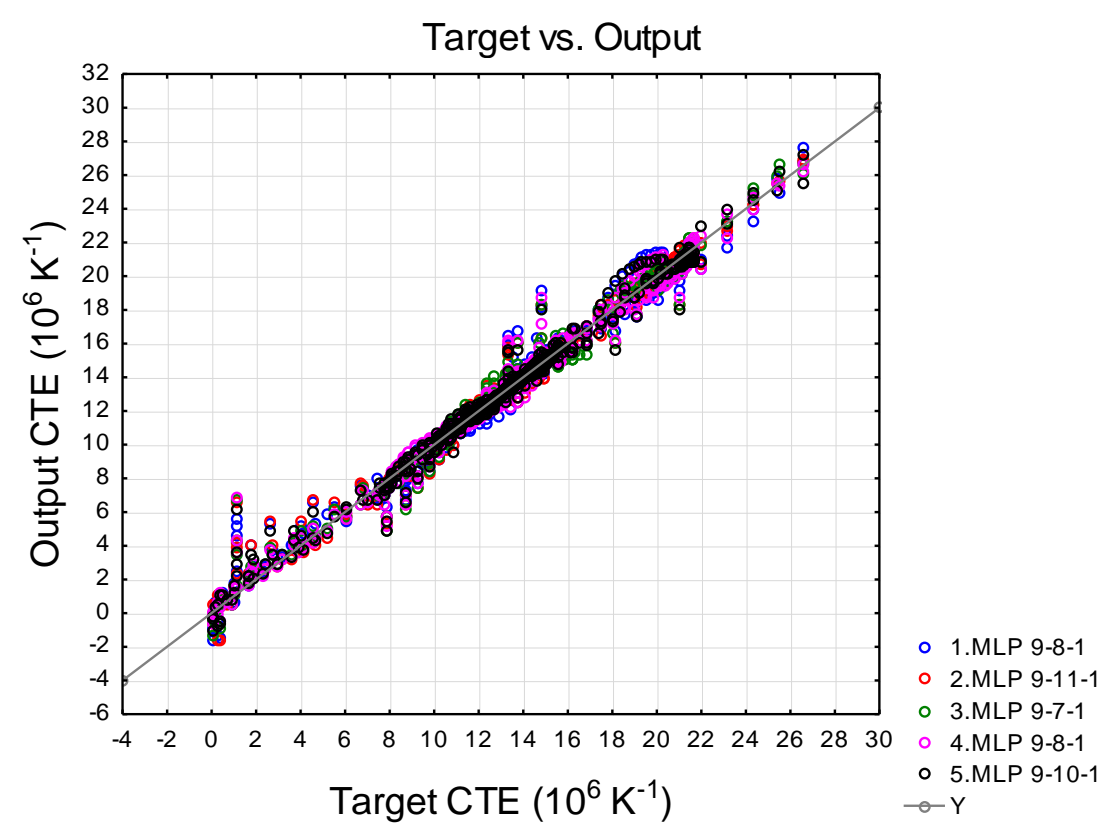

Figure 3 Performance of the best five ANN architectures 
testing of generalization capability. Comparison with measurement on TMA (Figure 4) device shows good accordance of results.

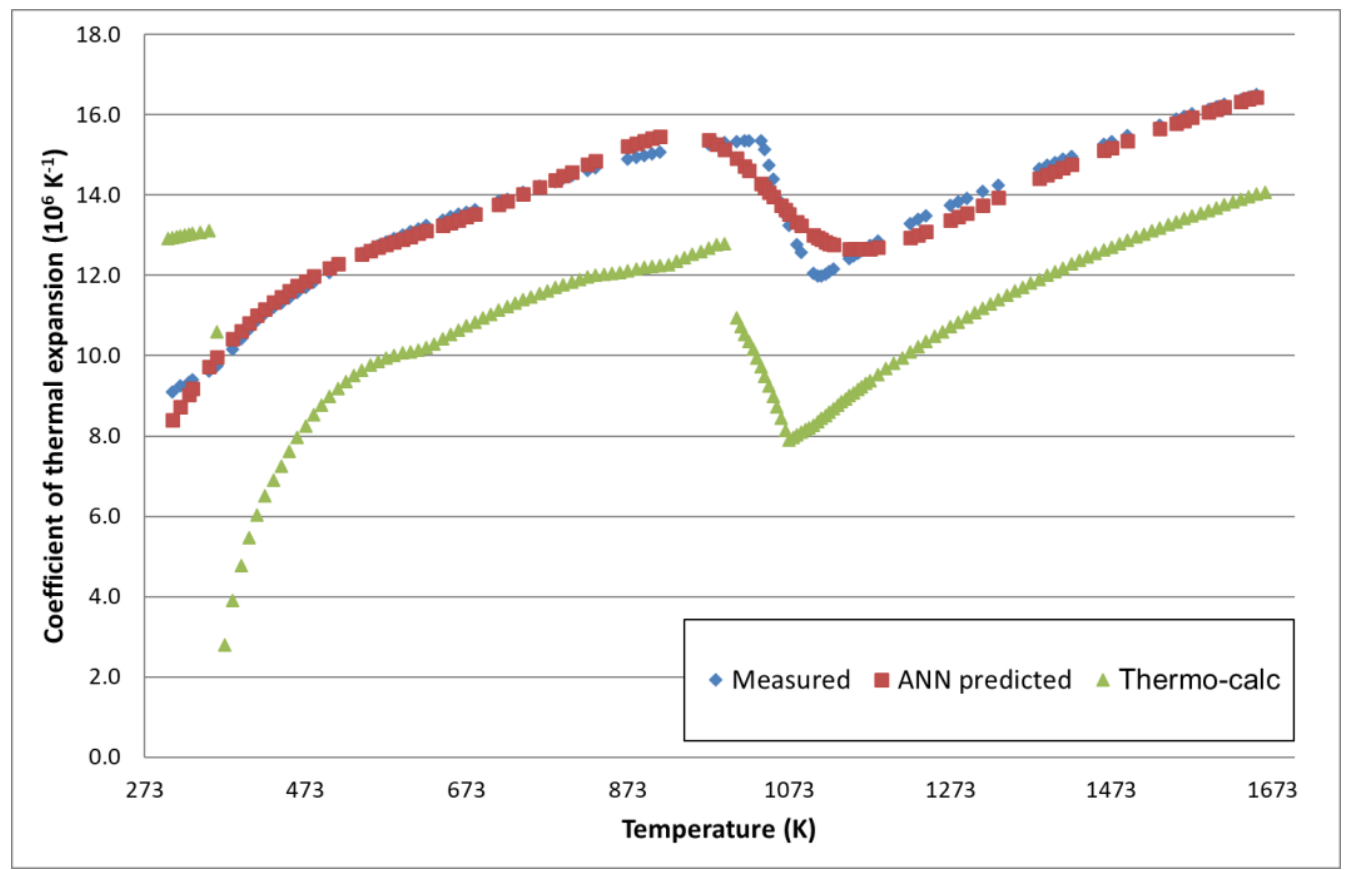

Figure 4 Results comparison

Figure 4 also shows comparison of measured values of CTE and computed by routine proposed by author [10] which is based on relation between CTE nad temperature dependant change of volume computed by software Thermo-Calc. Correlation between values predicted by MLP 9-8-1 network model and those measured is shown in Figure 5 with high coefficent of determination $R^{2}=0.96$. Mean deviation between predicted and measured values is under $2 \%$ with maximum of $8 \%$ both sides especially at room temperature or near austenite decomposition start and end temperatures.

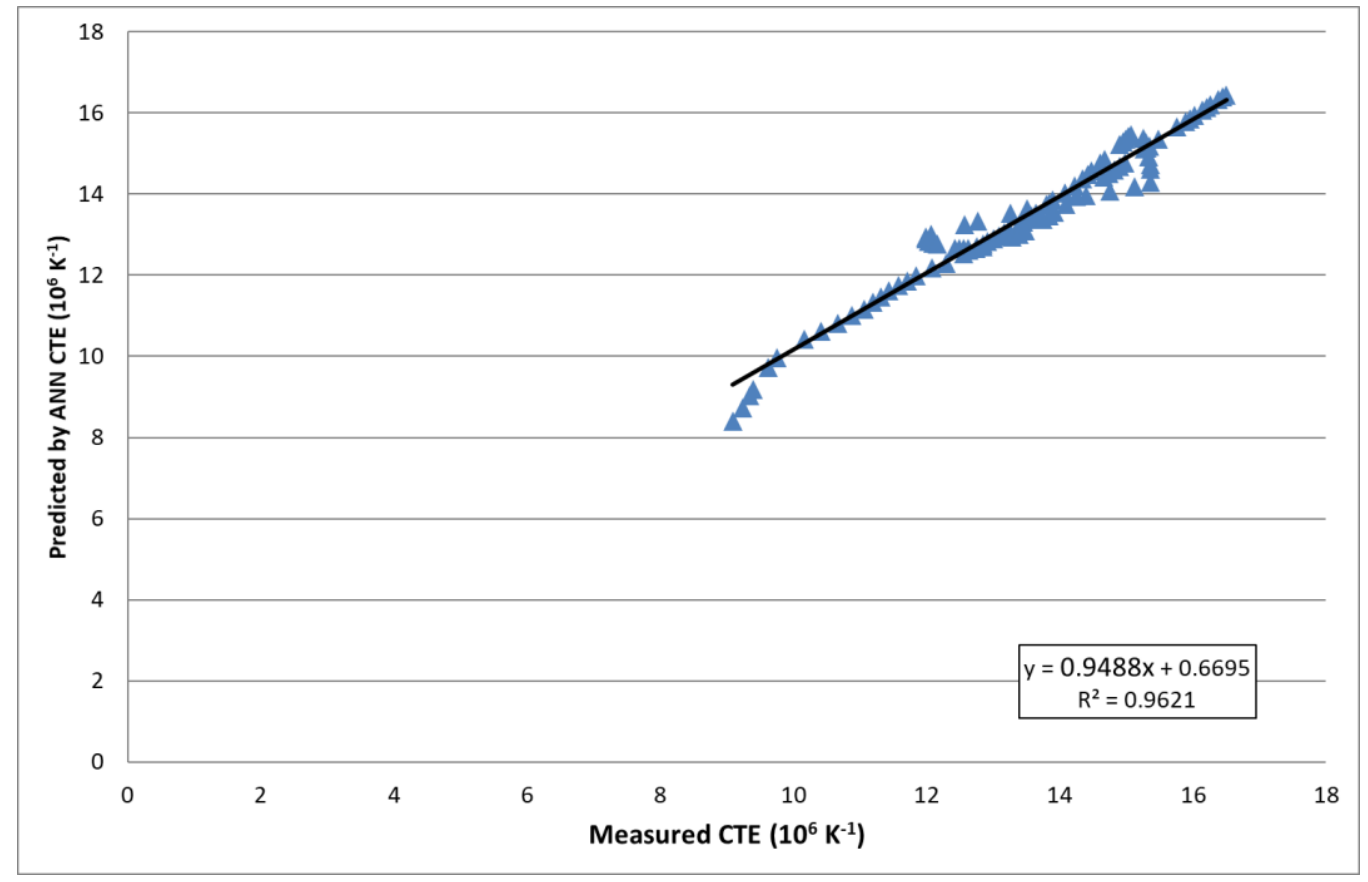

Figure 4 Correlation between model and real data for steel grade 12 


\section{CONCLUSION}

Good accordance of predicted values of CTE with those measured shows ability of artificial neural network to model thermophysical properties dependant on composition of steel and temperature. Of course there is still need to find optimal architecture of network with aim to get even higher value of the coefficient of determination which is certainly possible as cited references proof.

One of the way is widening the data for building such network especially collection data for more steel grades with better distribution of alloying content. Also consistent data set by means of method of CTE measurement would help because differences between values from different methods are not negligible. Future work should focus on creating a comprehensive collection of thermophysical properties for tens or even hundreds steel, cast iron or iron alloys in general to develop highly reliable tool to predict properties values of new alloy grades developed by material engineers.

\section{ACKNOWLEDGEMENTS}

This paper was supported in the frame of TAČR reg. no. FW01010097 Automated systems in the field of ladle metallurgy, students projects SP2020/34, SP2020/39, SP2020/89, (Faculty of Materials Science and Technology) and "Support of gifted students of doctoral studies at VŠB-TUO" no.: 04766/2017 / RRC (Moravian-Silesian Region).

\section{REFERENCES}

[1] ŽMAK, I., FILETIN, T. Predicting thermal conductivity of steels using artificial neural networks. = Predicting thermal conductivity of steels using artificial neural networks. Transactions of FAMENA. 2010, vol. 34, no 2, pp. $11-20$.

[2] MACHU゚, M., DROZDOVÁ, L., SMETANA, B., ZIMNÝ, O., VLČEK, J. Estimation of liquidus temperatures of steel using artificial neural network approach. In METAL 2018: 27th International Conference on Metallurgy and Materials. Ostrava: TANGER, 2018, pp. 55-62.

[3] CONDUIT, B.D., JONES, N.G., STONE, H.J., CONDUIT, G.J. Design of a nickel-base superalloy using a neural network. Materials \& Design. 2017, vol. 131, pp. 358-365.

[4] MACHU゚, M., DROZDOVÁ, L., SMETANA, B., ZLÁ, S., KAWULOKOVÁ, M. Artificial neural network usage for determining solidus temperature of steels. In METAL 2019: 28th International Conference on Metallurgy and Materials. Ostrava: TANGER, 2019, pp. 48-53.

[5] KOLEY, S., RAY, T., MOHANTY, I., CHATTERJEE, S., SHOME, M. Prediction of electrical resistivity of steel using artificial neural network, Ironmaking \& Steelmaking. 2019, vol. 46, no. 4, pp. 383-391.

[6] LÓPEZ-MARTíNEZ, E. et al. Artificial Neural Networks to Estimate the Thermal Properties of an Experimental Micro-Alloyed Steel and Their Application to the Welding Thermal Analysis. Strojniški vestnik - Journal of Mechanical Engineering. 2015, vol. 61, no. 12, pp. 741-750.

[7] WANG, J, van der WOLK, P.J., van der ZWAAG, S. Determination of Martensite Start Temperature in Engineering Steels Part I. Empirical Relations Describing the Effect of Steel Chemistry. Materials Transactions. 2000, vol. 41, no. 7, pp. 761-768.

[8] BANO, N., NGANBE, N. Modeling of Thermal Expansion Coefficients of Ni-Based Superalloys Using Artificial Neural Network. Journal of Materials Engineering and Performance. 2012, vol. 22., pp. 952-957.

[9] DESAI, P.D., HO, C.Y. Thermal Linear Expansion of Nine Selected AISI Stainless Steels. AISI, 1978.

[10] KALUP, A. Study of Selected Thermodynamic Properties of Metallic Systems with use of Thermal Analysis Methods. Ostrava, 2017 Ph.D. Thesis. Technical university of Ostrava. 